\begin{tabular}{l}
$N o r d i s k$ \\
\hline
\end{tabular}

\title{
Susanne JANSSON
}

\section{Style As Experience}

A couple of weeks ago the motion-picture The Matrix, by the Wachowski brothers, opened in Sweden. I read Jan Söderquist's review of it in Svenska Dagbladet, on the 14th July. His point was that The Matrix was a very good example of what he understood as a new trend in Hollywood movie making, a trend where style is all, and plot, development of themes etc., count for almost nothing. I saw the film. It was like attending a fashion show, or a little like a chain of commercial spots - and added to that a lot of strangely formalized yet disgusting violence. Now, I start with this example just to single out "trademark style." By trade-mark style I mean the kind of style that can be analysed, in the sense that one easily separates style features, e.g. as a number of brands and trade-marks of clothing-details, hair-styles, fashion attitudes, gestures, etc. I am talking about style that can be sorted. (The expression "trade-mark style" emanates from the fact that one can easily give examples from commercialism. But, of course, by this simplification I do not exclude non-commercial examples.) In fact, a parallel to this would be the case of the term aesthetics; "simplified aesthetics" - compare trade-mark-style - would be when people consider aesthetics as nothing but decorative elements. - Of course, I hope to be able to say something about style, that cannot be sorted, style as immersed, style that cannot be analysed, yet rationally reflected upon. And, for the sake of simplicity, I shall make a distinction, in the following, between trade-mark-style and style that glows - "glowing style."

$*$

Now, I started writing this paper by looking up the word "style" in Webster's Dictionary. It read: Style from Latin "stilus", "an iron-pointed instrument for 
writing on wax tablets; also, a manner of writing", and "manner or mode of expression in language; way of putting thoughts into words."

Taken together these two uses of the word "style" suggest a rift and a bridge between something external, namely the "writing with a pen," and something internal, namely the process of thinking. The bridge aspect comes out as the perfect match between the two, the perfect match between writing and thinking.

Take Mozart's scribbled score for some musical ideas in The Magic Flute, exhibited at the Uppsala University Library. I have the impression that it is all there - Mozart's music as well as his actual movements in a room, a particular room, i.e. in the sense that the autograph, the action of writing, in this case, shows his particular and characteristic ways of making marks in an environment. - From where emanates my notion of an integrated whole, here, an integrated whole that keeps me fascinated. Is it just wishful thinking? Is it just my reverance for Mozart's canonical status? Or is it of some real consequence, aesthetically speaking? Obviously, I settle for the last question and suggestion. However, I admit that I shall never be able to analyse the links between that autograph and the music. - When dealing with style I imagine that one always arrives at this inexplicable yet compelling rift-and-bridge of style (whatever this means). Style straddles. As a reader, spectator, I am ready to penetrate the surface of style for what it is worth! And it can of course be the case that style is worth nothing. I find it interesting that we are prepared to conceive of style in semantic terms: style means something; style is experience, etc.

At first I observe the surface of style, and then I sense this surface of style as experience. Now, how does this translation occur, how does this new correspondence, occur? Well, I would say that it occurs in the sense that the surface, the screen of style, starts glowing from behind. And what would that mean? What the answer is, I cannot tell, but it seems to me, that, in the ways we interact, there is this "glowing from behind," now and then. And what is interesting, here, is the fact that there are no rules for how it happens, now and then.

So, as a temporary conclusion: Why "style?" (i) Because style is not restricted to any particular domain of art, but applies to many different situations; (ii) because style can be considered a repertoire of behaviour and expressions characteristic of an individual; (iii) because style has a certain uniformity about it; (iv) because style is, can be, a screen that glows.

If one ponders over it, it might appear as though the concept "style" of the enumeration above, could be replaced by "character." Furthermore, to 
some, "character" might seem more appropriate than style, because these same people conceive of style in its trade-mark sense, namely as a pure surface phenomenon. However, from my point of view, the word character implies too mucb of "inner qualities," which easily turns into black-box-bogus that I want to free myself from - hence style. Style straddles like a glowing screen straddles....

Webster's Dictionary said that style is a manner of writing. Call it the graphical definition (from grapbology). Dancing, choreography, obviously falls within the catchment area of this definition - if expanded. My proposal is, along these lines, that all performing arts for example, and maybe performances in general, relate to the graphical definition. It means that even drawings, which are executed with a stilus, or something like it, fall under this definition. And what if paintings did not emerge out of performative acts? - Take Rembrandt's stroke with the paint-brush, at the same time marking the surface and suggesting "a behind" - the same straddling rift-bridge connection as Webster's: manner of writing and manner of thinking.

We would agree, wouldn't we, that meeting someone for the first time and being way into deep acquaintance, are in part different states. There is much, say about his or her biography, that one learns along the way: (i) The first time we met I noticed a minor scar on his forehead, but I dared not ask about it. Later I learned about it. Now another example: (ii) I observed that his hair was gray despite his young age. I later learned that his gray hair came overnight, due to a tragic loss in the family. And finally this example: (iii) after some time of acquaintance I really knew his style; in a positive sense there was a "heart of style" about him, and I felt how it had all come about, in the light of what he had been through, in the light of his experiences. (The expression "heart of style" sounds somewhat paradoxical, nevertheless I believe it says something.) - We notice that in (i), the scar example (he fell off his bike when he was a kid) and in (ii), the gray hair example, causality works. However, in (ii) a cascade of memories and attachments caused the color shift of his hair, as well as his whole outlook on life. Now, in (iii), the heart-of-style example, there is no simple cause, nor even a complex cause, but something which shows, something which is backed up by experience. So far, so good. As I reflected on his "heart of style" as something I learned underway I suddenly realized that it was something I had noticed when we first met! In fact I noticed it as clearly as I saw that scar on his forehead! - This is what is so striking: style has all the immediacy that a surface can offer, and it lasts as all kinds of cherished objects of attention. 
A few words, now, about the turn of my third heart-of-style example (iii) above, by which I return to my first impression, of a heart of style. What I am going to say is obvious, still important to point out, namely, that experiences might differ while style remains the same. I presume the person I was talking about above will be recognized by his heart of style also tomorrow; that is: coming events might affect his style but not drastically transform it.

There is something else that I would like to add here, namely, that focussing on style means keeping a certain distance to the notion of expression, or to the notion of expressionism, generally speaking. Why? Well, saying that a "style expresses" something sounds odd, to say the least. It sounds odd, because a style is what it is. Compare "expression" which is not what it is; an expression channels or releases something having its origin in deeper regions; someone sighs, thereby expressing an inner fatigue, for example.

Now, the Mozart autograph again. Someone who could make out the melody fragments and also sing them in his or her head, would not that person be granted something extra, a certain flavour of style, a certain intimacy that style affords, as compared to someone reading the same score in print? The printed score could be left behind, but not the autograph. The printed score could be left behind because it shows no traces of intimacy.

Now, let us reflect upon heart-of-style and straddling-style in relation to a literary example. Raymond Chandler is definitely into style. His short-story I'll be waiting is a good example; it is about the house-detective Tony Reseck's caring for a young woman in a jam. It starts late at night in a deserted hotel lobby and ends in the same location. Further, very little happens. Reseck and the young woman talk to one another intermittently, there's a phone call, music from a radio, etc. What interests me particularly, here, is the style of Reseck. This is how the story begins:

At one o'clock in the morning, Carl, the night porter, turned down the last of three table lamps in the main lobby of the Windermere Hotel. The blue carpet darkened a shade or two and the walls drew back into remoteness. The chairs filled with shadowy loungers. In the corners were memories like cobwebs.

Tony Reseck yawned. He put his head on one side and listened to the frail, twittery music from the radio room beyond a dim arch at the far side of the lobby. He frowned. That should be his radio room after one a.m. Nobody should be in it. That red-haired girl was spoiling his nights.

The frown passed and a miniature of smile quirked at the corners of his lips. He sat relaxed, a short pale, paunchy, middle-aged man with long, delicate fingers clasped on the elk's tooth on his watch chain; the long delicate fingers of a sleight-of-hand artist, fingers with shiny, moulded nails and tapering first joints, fingers a little spatulate at the 
ends. Handsome fingers. Tony Reseck rubbed them gently together and there was a peace in his quiet sea-gray eyes.

The frown came back on his face. The music annoyed him. He got up with a curious litheness, all in one piece, without moving his clasped hands from the watch chain. At one moment he was leaning back relaxed, and the next he was standing balanced on his feet, perfectly still, so that the movement of rising seemed to be a thing imperfectly perceived, an error of vision. (Raymond Chandler, Trouble is My Business, Penguin Books, 1954, p 125)

That was the beginning. And here follows the end of the story....

Tony nodded at the clerk and smiled a minute frail smile. He put his handkerchief away and patted the pocket he had put it in. He turned and walked away from the desk, across the entrance lobby, down the three shallow steps, along the shadowy reaches of the main lobby, and so in through the arch to the radio room once more. He walked softly, like a man moving in a room where somebody is very sick. He reached the chair he had sat in before and lowered himself into it inch by inch. The girl slept on, motionless, in that curled-up looseness achieved by some women and all cats. Her breath made not the slightest sound against the vague murmur of the radio.

Tony Reseck leaned back in the chair and clasped his hands on his elk's tooth and quietly closed his eyes. (p 143)

My impression is that the establishment of a characteristic style, Reseck's style, which lasts through the story, is also the theme and the value of the story, in a sense. - This, then, is one level on which style is of importance to Chandler. Then there is Chandler's "manner of putting thoughts into words" of course. That is something else, another level, in the sense that he wrote other stories, in this manner. Now, how do these two domains of style relate to one another in this case? I would like to propose that Reseck's presence, his movements, his manipulations (elk-tooth), yes, his style, his heart of style, somehow reflects Chandler's "manner of putting thoughts into words." How would that be possible? Well, I do not know how that would be possible, yet there is a certainty about my observation of affinity, here, i.e. of Reseck's and Chandler's "respective" styles.

In a sense Chandler, as above, is a choreographer. The way Reseck and the woman, move, is kind of a pas-de-deux. Let this bring us to dancing as style. Isn't it the case that when movements are considered as being part of dancing, then we attend to style? Now, there is a whole range of gestures and movements in everyday life that has a dance-aspect to them - just as obviously as that there are gestures and movements in dancing, which have an everyday life aspect to them. What I am trying to get at, is, that dancing is mixed up with life 
all along the way, and that this dance aspect is very much an aspect of style. The dancing of everyday life is a kind of writing, in which the dancer is the stilus, the dancer is style. And when the dancer is style, he or she exemplifies the rift-bridge, or the straddling of style.

Let us consider style and author. Now, there is an interesting anonymity about style. By penetrating style one does not come closer to the person. Compare psychology, which in some of its forms, strives to probe the depths of individual minds. Nothing of that is the case when considering the style of an individual. When we observe the style of Reseck, or a dancer, or a friend, we do not in any sense of the word, invade this person, nor disclose anything hidden about him or her. Style occurs in between us; it is common and shared as is grammar. In close relations, as between husband and wife, for instance, there is of course a listening to the heart of one another, a mutual caring for the soul, because, husband and wife are not attached to one another solely through style, one would hope. Again, this does not mean to say that style is superficial. Remember we talked about a "heart of style" earlier. It, the heart-of-style, belongs to the situation in which we interact with one another. - Think about what sometimes happens after having taken farewell of a person. It might very well be, sometimes, that what stays in one's mind is his or her style, and this is not a depreciation of his or her very person. On the contrary, I feel grateful to him or her for having communicated to me a particular sense of style, because it meant I was presented with a heart-of-style.

Let us now consider what it means to reflect upon style as compared to making interpretations. The point about making an interpretation, must it not be that it takes a number of steps of thinking to arrive at the hidden meaning of a certain object or message or presentation? In the case of style, there is no hidden message or meaning, hence no interpretation of style. But there are subtleties to account for, which, I suspect, is what the critical enterprise is all about. I repeat and conclude: "my" critique does not embark on the road of interpretation but accounts for subtleties. "Accounting for subtleties" is making oneself aware of a heart-of-style. - Another approach- to style and interpretation is this: it is obvious that evidence can be fragmentary. In such a case there might be more than one interpretation to account for that evidence. But style, what is "fragmentary style?" Nothing. Style is more like an on-or-off process. Someone with style, whatever that means, could suddenly loose his or her style, even pick it up later, but "being partly in style," is a misnomer. 
The basis and background of my understanding of style is Wittgenstein's notion of primitive reactions. My subtleties-of-style have much in common with Wittgenstein's primitive reactions, namely in that primitive reactions, like subtleties of style, are open to inspection; both primitive reactions and subtletiesof-style, are like cards played open. - Another aspect: could there be hidden style? True, a falsifier could hide his or her own hand-writing, by imitating somebody else, but as I read the false autograph, then I do not read a hidden hand-writing. - Yet another aspect: there are no symptoms of style. As we have said, repeatedly: style is style. Now, saying that style is not symptomatic, means that experience does not enter the way it does when for example a person starts blushing. Rather, style is "formalized experience" - I cannot come up with anything better than this for the moment....

And here follows yet another, in a sense negative way of coming to grips with the notion of style: style is not paraphrase or metaphor - style is not a replacement of anything, nor a substitute of some kind. But style is an aspect, and aspects are - as Wittgenstein tells us - either dawning or striking. So, I would say that style is something striking or something dawning, i.e. the appreciation of style does not follow from some analytical reasoning, but happens like lightning and sunrise, and one cannot avoid noticing the lightning or the sunrise, when this or that happens. On the contrary: one exclaims: "OHHHH!" which of course is a primitive reaction.

We have talked about heart-of-style and about subtleties-of-style. Now, how are these notions accounted for? Well, style can be shaped by all and everything that we experience, therefore style affects us, therefore style is subtle.

*

Up to now I have focused very much on style as pertaining to individuals and individual behaviour. Now I want to say something about how style relates to the context of a situation, because style is always part of a scene and a setting. Take Tony Reseck again; his style is "enacted" in the peaceful yet somewhat spooky atmosphere of that night in the Windermere Hotel lobby. Remember:

At one o'clock in the morning, Carl, the night porter, turned down the last of three table lamps in the main lobby of the Windermere Hotel. The blue carpet darkened a shade or two and the walls drew back into remoteness. The chairs filled with shadowy loungers. In the corners were memories like cobwebs. 
Tony Reseck yawned.

We notice that Chandler starts his story by establishing an atmosphere. It does not take him more than a few lines. Then suddenly we meet the protagonist: "Tony Reseck yawned" and so on... Notice that Reseck's yawning starts in the sleepy atmosphere of the lobby. And now we have all that is needed: actor and set. It is this unity of "actor and set" that is of interest to us now; I shall call that unity "mode of presence." I call it mode of presence because, just as much as the actor is being affected by the atmosphere of the room (remember the yawning), so does the atmosphere of the room absorb, or reflect the style of the actor. And of course, modes of presence vary.

I shall not say more about modes-of-presence here, but touching on it this briefly, is hopefully enough for making it clear that style can no more be accounted for in isolation than could music cut off from sounding boards of some kind. 